\title{
Modelling the impact of earthquake activity on real estate values: a multi-level approach
}

\author{
Berna Keskin, Richard Dunning and Craig Watkins \\ Department of Urban Studies and Planning, University of Sheffield, \\ Sheffield, UK
}

Abstract

Purpose - This paper aims to explore the impact of a recent earthquake activity on house prices and their spatial distribution in the Istanbul housing market.

Design/methodology/approach - The paper uses a multi-level approach within an event study framework to model changes in the pattern of house prices in Istanbul. The model allows the isolation of the effects of earthquake risk and explores the differential impact in different submarkets in two study periods one before (2007) and one after (2012) recent earthquake activity in the Van region, which although in Eastern Turkey served to alter the perceptions of risk through the wider geographic region.

Findings - The analysis shows that there are variations in the size of price discounts in submarkets resulting from the differential influence of a recent earthquake activity on perceived risk of damage. The model results show that the spatial impacts of these changes are not transmitted evenly across the study area. Rather it is clear that submarkets at the cheaper end of the market have proportionately larger negative impacts on real estate values.

Research limitations/implications - The robustness of the models would be enhanced by the addition of further spatial levels and larger data sets.

Practical implications - The methods introduced in this study can be used by real estate agents, valuers and insurance companies to help them more accurately assess the likely impacts of changes in the perceived risk of earthquake activity (or other environmental events such as flooding) on the formation of house prices in different market segments.

Social implications - The application of these methods is intended to inform a fairer approach to setting insurance premiums and a better basis for determining policy interventions and public investment designed to mitigate potential earthquake risk.

Originality/value - The paper represents an attempt to develop a novel extension of the standard use of hedonic models in event studies to investigate the impact of natural disasters on real estate values. The value of the approach is that it is able to better capture the granularity of the spatial effects of environmental events than the standard approach.

Keywords House prices, Earthquake activity, Multi level modelling, Hedonic regression

Paper type Research paper

(C) Berna Keskin, Richard Dunning and Craig Watkins. Published by Emerald Group Publishing Limited. This article is published under the Creative Commons Attribution (CC BY 4.0) licence. Anyone may reproduce, distribute, translate and create derivative works of this article (for both commercial and non-commercial purposes), subject to full attribution to the original publication and authors. The full terms of this licence may be seen at http://creativecommons.org/licences/ by/4.0/legalcode

The findings of this paper are derived from a project funded by the RICS Education Trust. This project also informed the chapter "Using Multi Level Modeling Techniques as an AVM Tool: Isolating the Effects of Earthquake Risk from Other Price Determinants", pp. 209-223, in Advances in Automated Valuation Modeling: AVM After the Non-Agency Mortgage Crisis, Volume 86, in the series Studies in Systems, Decision and Control, published 2 February, 2017.

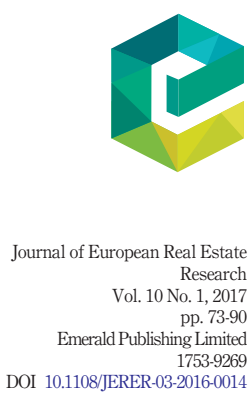


JERER

10,1

74

\section{Introduction}

There is a voluminous international literature that explores the impact of earthquake risk on housing prices. This research agenda has been motivated by the need for a variety of stakeholders, including valuers, estate agents, policy makers and mortgage lenders, to be able to accurately estimate the way in which changing perceptions of the risk of damage could alter property values over space and time (Onder et al., 2004). Broadly, within the literature, there have been two main methods used to derive estimates of the impact of the risk of damage on property values. The first of these uses hedonic house price models to isolate the impact of earthquake risk from the effects of other physical, neighbourhoods and locational determinants of property values (Nakagawa et al., 2007; Naoi et al., 2009). The second method uses survey methods to capture revealed preferences or to identify the willingness to pay to reduce risk (Palm, 1981; Willis and Asgary, 1997). Irrespective of the approach used, the majority of the empirical estimates have been derived from what are often referred to as "event studies". Event studies are those where current (or recent) estimated values are compared with those derived prior to some significant shock that a priori might have altered perceptions of risk to property (Beron et al., 1997).

This paper seeks to introduce a new approach to estimating the impact of environmental change, such as earthquake activity, on real estate values. Specifically, the paper applies multi-level modelling techniques within an event study framework. Multi-level methods have been around for some time, but it is only in the past few years that they have become much more commonly used in real estate research (Feng and Jones, 2016; Keskin, 2010; Leishman, 2009; Orford, 1999). The novelty of this paper comes from using these methods as a means of undertaking the comparative analysis of a housing market at two discrete time periods. The existing literature suggests that this approach may be superior to the use of hedonics in event studies, because the models allow for a more granular understanding of the spatial dimensions of the impact of changes on environmental risk (Leishman et al., 2013).

The empirical analysis draws on data from the Istanbul housing market. Istanbul provides a useful case study for the exploration of the impact of earthquake risk because of its recent history of earthquake activity. Notably, in 1999, the Marmara earthquake had significant economic effects on Istanbul and had a very direct impact on real estate values within the city (Bibbee et al., 2000; Onder et al., 2004; Alkay, 2008; Keskin and Watkins, 2014). More recently, in 2011, there has been earthquake activity in the Van region in Eastern Turkey. Although it was not sufficiently proximate to cause direct property damage, it appeared to heighten concerns within the study area about the risk of damage throughout the geographic region (Wenzel et al., 2012).

Thus, the overall aim of this paper is to apply multi-level modelling techniques to the estimation of the impact of earthquake risk on real estate values before and after local activity. Our hypothesis is that even though the Van earthquake did not directly impact Istanbul, when coupled with the relatively recent memory of the Marmara quake, this activity in the broader region has had an impact on the perceived risk of earthquake damage. We anticipate that this impact will be revealed in statistically significant changes to constant quality house prices in the parts the Istanbul market is thought to be most at risk. The spatial richness of the modelling framework allows us to make detailed comparison of the impacts on different spatial housing submarkets. In line with standard hedonic analysis, the modelling framework also allows us both to control for the impact of other market changes on the value of housing attributes and to isolate the influence of the risk of earthquake damage from the other determinants of house prices.

To test the hypothesis that the price effects of earthquake risk have changed since 2011, the analysis was undertaken in three stages. First, a baseline multi-level model was developed for a period (2007) prior to any earthquake activity. This allowed us to establish 
equilibrium prices and to identify the "standard" post-Marmara influence of perceived earthquake risk. Second, a second model was developed to explore the extent to which a recent earthquake activity in the wider geographic region might have altered the impact of perceived earthquake risk on prices within the Istanbul housing market. This model adopted the same structure as the baseline model and allowed us to compare the changes in different determinants of house prices, including earthquake risk. The ability to control for a variety of different determinants of house prices is important given that the Istanbul market has been highly dynamic over the study period (Coskun, 2011). As Alkay et al. (2015) explain, by 2012, new construction activity had risen to 6 per cent of GDP (one-third higher than a decade before), with nominal house price inflation at 110 per cent between 2010 and 2014. Third, the spatial patterns of earthquake risk in the study area before and after what we hypothesize was a significant perception altering event were compared. This allowed us to provide estimates of the changing spatial impact of risk in a form that is accessible to market actors and policy makers.

The paper has four further sections. Section 2 outlines the complexity of modelling the spatial impact of shocks (in particular, natural disasters) in urban housing markets. The review considers, in particular, the different ways in which alternative approaches capture either spatially smooth distance-decay processes or discrete, and lumpier, submarket (market segment) specific effects. This section also explores the existing literature on the impact on housing markets of earthquakes. Section 3 introduces the study area, discusses the Istanbul real estate market context during the study period and sets out the research design. Section 4 presents the results. The paper concludes with a brief discussion of future extensions of the modelling approach introduced here.

\section{Modelling the impact of shocks on property values}

Risk in housing markets emerges for a wide variety of sources, including in some contexts natural environmental disasters. Natural disasters occur at different geographical scales, with different levels of predictability about their likely spatial impacts. Different types of disasters have varying and differentiated geographic effects upon the built environment and upon the perceptions of risk in the housing market. These variations mean that modelling the spatial and temporal impact of events that "shock" property values can be very complex.

In real estate studies, the analysis of such impacts has tended to be based on the application of the hedonic regression modelling technique and its variants (such as spatial interactions models). The conceptual basis for hedonic analysis is fairly simple: households place a value on each of the dwelling attributes. When multiple transactions occur, it is possible to compare the overall price paid in each transaction and the various attributes (variables) belonging to each of the dwellings exchanged. Regression analysis can then help to identify the average value consumers placed on each of the individual attribute. In the case of housing, this can relate to a large number of variables. For example, number of rooms, size, age, presence of heating/air conditioning and locational characteristics are all routinely used, in addition to many other possible variables. In housing studies, hedonic models have frequently proved to be useful and readily modifiable, with the ability to consider different variables in different settings with a view to isolating and understanding the importance of each different variable in house prices (see Malpezzi, 2003 for an excellent review).

Des Rosiers and Theriault (2008) outline three reasons to use hedonic regression methods in studies of real estate values. First, multiple regression analysis uses probability theory to divide the impact of competing influences on house prices. Second, they argue that its calculative nature is objective and therefore more likely to produce the market value that fits a testable probability distribution. Third, hedonic approaches reveal the causal dimensions 
JERER 10,1

76

of house pricing and when combined with Geographic Information System (GIS), or applied in expanded form, can discern the spatial dimensions of price formation too.

Not surprisingly, given the flexibility in specification, hedonic techniques have been applied in an attempt to understand the impact of human and natural disasters. Environmental issues have been a particularly frequent theme in the hedonic literature (Ridker and Henning, 1968). This vast literature covers issues such as noise pollution, water contamination and proximity to hazardous waste sites or overhead powerlines (see Boyle and Kiel, 2001 for a review of 30 papers). Hedonic models are also frequently utilized in understanding the impact of natural disasters, such as flooding (Macdonald et al., 1987; Bin et al., 2008), forest fires (Loomis, 2004; Mueller et al., 2009; Stetler et al., 2010) and hurricanes (Simmons et al., 2002; Hallstrom and Smith, 2005). While the precise form of the model and research design varies in many of these papers, the basic proposition is that the application of a hedonic regression framework makes it possible to discern a discount in property prices that reflects the impact (or risk) of one of these negative external events.

The number of papers that directly use hedonics to measure earthquake effects is, however, fairly modest. One important contribution, given our empirical focus on Istanbul, is the study undertaken by Onder et al. (2004). The paper seeks to determine if the 1999 Marmara activity has an impact on house prices. This study uses a quasi, rather than pure, hedonic approach in that the dependent variable is the change in price between 1995 and 2000. This is regressed against a very parsimonious set of variables, set within a quadratic functional form, where earthquake risk is proxied by soil quality and distance from fault lines. The results show that the price effects are most significant in areas that, because of soil type and proximity to fault lines, are perceived to have high risk of earthquake damage.

The study by Nakagawa et al. (2007) adopts a more conventional hedonic approach. This paper models housing rents in Tokyo in 1998 in attempt to find evidence of the influence of earthquake-resistant construction standards and household perceptions of earthquake risk. The model takes a logarithmic functional form and uses data from more than 82,000 buildings. The authors included dummy variables to indicate the existence of 23 separate neighbourhoods (wards) as a way of controlling for locational effects. The structure quality variables are highly significant. The results demonstrate that investment in earthquake-proof structures enhances investor returns to such an extent that any costs are greatly exceeded by enhancements to future income streams.

The studies that use this type of simple hedonic regression approach tend to assume that market actors have the ability to factor relevant information into their house price calculations. In the case of natural disasters, market actors use information on the likelihood of an event to inform bidding and selling strategies perfectly. Conceptually, hedonic models treat the housing market as being in multiple equilibria. The implicit price of any attribute will change over time if the information set changes. This change can be measured by re-estimating the hedonic function at different points in time.

There are numerous ways with which the spatial variations in the impact of different price determinants might be modelled. The most simplistic hedonic models view space as a continuous plain, where the impact and perception of natural disasters are equally distributed across the plain. These assumptions enable a simplified model of house price formation. The paper by Onder et al. (2004), discussed above, illustrates how this model can be applied to discern spatial difference in price effects.

Hedonic models of this sort have been extended in multiple ways to respond to this challenge of spatial variation in the value of different hedonic characteristics. Some attempts have been made to conceptualize and model the variation in house prices that change evenly over Cartesian space using augmented hedonic regression techniques (Clapp, 2003, see also 
Pavlov, 2000 for a non-parametric approach, using K-nearest neighbour analysis). These approaches are intuitively appealing because they remove the need for the researcher to have or obtain knowledge of spatial boundaries and simply allow the spatial variations in price to emanate from the data, be smoothed and therefore be predicted quite readily.

Elsewhere, the extensive housing submarket literature offers some pointers for dealing with spatial complexity (see Watkins, 2012 for a review). Definitions of submarkets do vary widely, but more nuanced approaches consider not only spatial contiguity but also differentiation in dwelling type and social structures (Watkins, 2001; Tu, 2003). These differences can be captured in models by using submarket dummies (Fletcher et al., 2000), spatial interactions terms (Fik et al., 2003) or by estimating a set of submarket-specific equations (Keskin and Watkins, 2016; Adair et al., 199;). The latter approach has been widely shown to be superior in that it reduces error and improves predictive accuracy (Goodman and Thibodeau, 2003; Watkins, 2001). This approach would have the potential to capture the variation in impact of earthquake risk between submarkets. This, however, can be difficult to operationalize in event studies, given that it is possible that submarket boundaries might have altered between study periods (Maclennan and $\mathrm{Tu}, 1996)$.

Nevertheless, the assumption of a stable submarket framework provides a platform from which researchers have been able to develop alternative approaches to measure spatial effects. Multi-level models are one such approach. Multi-level models are a variant of standard hedonic methods (Orford, 1999; Leishman, 2009). The use of multi-level methods is advised when the observations being analyzed are clustered and correlated, the causal processes underlying the relationships operate simultaneously at multiple spatial scales and where there is value in seeking to disentangle the spatial and temporal effects of different variables (Subramanian, 2010). Their use has begun to expand within the quantitative human geography literature where the technique has been used to explore a range of complex spatial impacts and interactions, including in the measurement of social well-being (Ballas and Tranmer, 2008). Again, conceptually, multi-level models allow analysts to treat the housing system as being in multiple equilibria, recognising the theoretical possibility of the co-existence of implicit markets for different attributes and of spatial submarkets across which the equilibrium value in the implicit markets can vary.

There is some compelling evidence that multi-level models add value in overcoming some of the challenges in capturing spatial differentiation in house prices. This is illustrated by Leishman et al. (2013), who compare the outcomes from four different housing market modelling strategies. Using a rich data set from Perth, Western Australia, they apply a standard market-wide hedonic equation; a system of submarket specific hedonic equations; and two variants of multi-level model models for the prediction spatial house price patterns. Their results suggest that the most spatially granular multi-level specification generates the greatest explanatory power and reduces the instance of non-random spatial errors.

Multi-level models, of course, do not normally have a temporal dimension and, as with hedonic models, this inability to capture market dynamics is an acknowledged weakness of the framework. Helpfully, elsewhere in the literature, analysts have sought to find ways to capture the changing spatial impacts of environmental events over time. For instance, Case et al. (2006) develop a hybrid hedonic/repeat sales model to explore the changes in the impact of environmental contamination annually over an 18-year period. The model contains a distance decay function that changes for each year of the study period. This approach has also been used by Lamond et al. (2010) to explore the impact of flood risk on prices. The weakness of the hybrid model is that the gains made in modelling spatial variations are bought by trading off the capacity to model dwelling-type heterogeneity. 
JERER 10,1

78
The approach used here seeks to build on the approaches described above. Our research design is based on the view that we can overcome the problem of dealing with spatial differentiation in housing market models by using multi-level methods and that it is possible to look at temporal change by locating these models within an event study design. We discuss the method more fully in Section 3 below. The remainder of the paper illustrates how this approach might be implemented. It is our view that this approach (at least partly) extends traditional models and is particularly useful in contexts where delineating the differences in the spatial impact of the risk of natural disasters is especially desirable.

\section{An applied case study - the impact of earthquake risk on property values in Istanbul}

3.1 Research design

The empirical analysis in this chapter focuses on the Istanbul housing market. Istanbul provides an excellent "laboratory" for several reasons. First, Istanbul is vulnerable to earthquake risk and, as such, the potential for damage has long been an important influence on housing transactions and on the behaviour of valuers, lenders and insurance companies. This was brought into sharp focus by the Marmara earthquake in 1999. This earthquake occurred along the North Anatolian Fault Zone and led to an estimated 45,000 casualties and damage (mainly beyond repair) to some 150,000 dwellings, leaving 300,000 people homeless. Significantly, for our study, this impact and the attendant perception of the risk of future activity have had differential impacts on different neighbourhoods and housing submarkets within the city, with the direct effects felt mainly in the Avcilar district to the west of the city (Onder et al., 2004). Second, although not directly affecting Istanbul, there has been recent earthquake activity in the Van region in Eastern Turkey, which when taken together with the memory of the impacts of Marmara, even though it has not immediately locally served to heighten awareness in Istanbul and throughout the wider geographic region. As such, the possibility that perceptions have been altered or reviewed provides a useful opportunity to see if heightened awareness of risk has led to changes in the pattern of house prices within the city and allows us to look at the sensitivity of real estate values to changes in perceived risk.

The modelling work is developed in three stages. First, a baseline multi-level model for a period (2007) prior to a shock to perceptions of the risk of earthquake damage in the Istanbul housing market was developed. Second, a model was established to explore the extent to which recent earthquake activity in the wider geographic region raised awareness of risk damage within the Istanbul housing market. Third, the spatial patterns of earthquake risk in the study area before and after a significant potentially "perception altering" event were compared and contrasted. Taken together, this allows us to explore the ability of the approach to distinguish the effects of inherently spatial influences on real estate values. It also allows us to illustrate how the model is able to capture the way these influences change at two different points in time.

\subsection{The Istanbul housing market}

The empirical analysis in this paper focuses on Istanbul, the largest city in Turkey. Istanbul is home to almost 15 per cent of the population of the country. The city is divided (almost half and half) into formal and informal housing stock (Building Census, 2000). The formal housing sector is dominated by market dwellings. The majority of the older, formal housing dwellings are located in high-density, inner urban neighbourhoods where much of the stock dates from the early twentieth century. This contrasts with newer dwellings that are found in a number of planned housing areas promoted by government since the start of the century. 
These newer areas emerged as a result of a concerted effort from policy makers to transform Istanbul from a monocentric to a polycentric city. Public investment was used to make infrastructural improvements and to pump prime industrial development in suburban locales. The private sector's development activity responded to the resultant changes in employment patterns and the transport network. Many of the properties in these non-traditional areas occupy the mid and higher end of the price scale. They are marketed in a way that reflects the growth in popularity of gated and semi-gated communities with good links to transport infrastructure, employment centres and high-quality public amenities (Alkay, 2011).

At the lower (informal) end of the market, there are significant numbers of unplanned dwellings, estimated by some to be just over 50 per cent of the total, located within squatter settlements known as "Gecekondu" (Gokmen et al., 2006). These neighbourhoods are occupied by lower income groups and consist of dwellings in poor physical condition and with limited sales values. Several of these areas have been subject to land market speculation and are starting to be transformed.

As Keskin and Watkins (2016) explain, although property values have been moving upwards, there has been evidence of increasing differentiation between submarkets at the cheaper end of the price spectrum and those at the top. Figure 1 illustrates the degree of spatial disaggregation within the market. Keskin and Watkins argue that these submarkets act as quasi-independent entities and offer a useful framework for the analysis of market change. In line with Pryce (2013), Watkins (1999) and Grigsby (1963), the submarkets identified comprise neighbourhoods that act as close substitutes, even though they are not always spatially contiguous. The most expensive areas are in Submarket 1, while the cheapest are in Submarket 5, which also happen to be the neighbourhoods traditionally perceived to be most likely to suffer earthquake damage. Keskin and Watkins show that, within Istanbul, the factors that shape house prices generally vary in relative importance at the neighbourhood levels. These differences are taken into account by selecting a modelling approach that allows these differential impacts to be revealed.

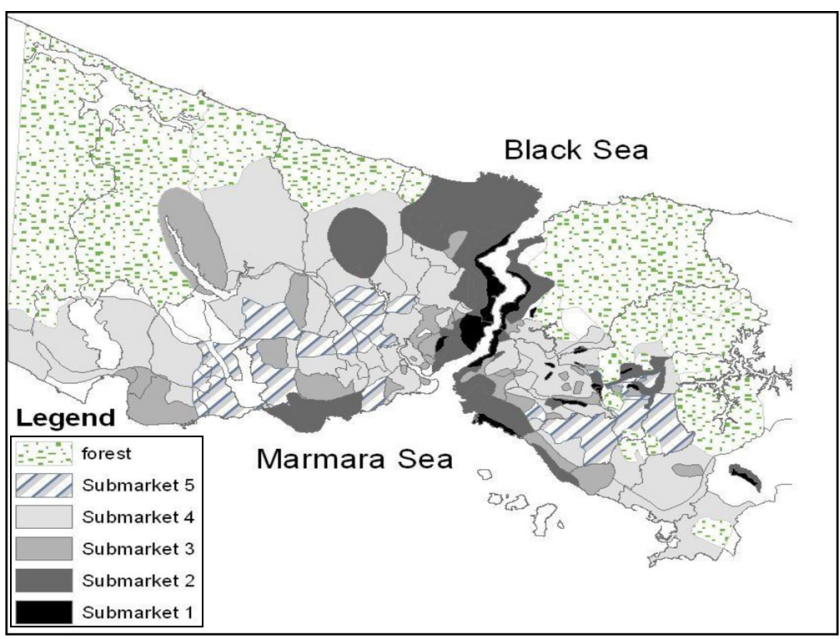

Source: Keskin and Watkins (2016)

Figure 1. Istanbul's housing submarkets 
JERER
10,1

80

\subsection{Data}

The house price and housing attributes data used for 2007 are drawn from the internet listing services of two leading realtors, Turyap and Remax. This data set consists of 2,175 observations from 348 submarkets constructed from 946 neighbourhoods in 32 districts. The price and attribute data have been combined with socio-economic, neighbourhood quality and locational characteristics obtained from a household survey undertaken by the Istanbul Greater Municipality in 2006. Data on earthquake risk, which have been shown to be significant in the past, were obtained from the Japanese International Cooperation Agency (JICA) report (JICA, 2002).

The database for 2012 was generated by using three data sets. The first data set was gathered from estate agents' website, Remax. This data set comprises 1,190 observations from 278 neighbourhoods in 39 districts. This was combined with household survey undertaken by Istanbul Greater Municipality and earthquake risk data from the JICA report. The variables are categorized into four groups: housing unit characteristics, socio-economic characteristics, neighbourhood quality characteristics and location characteristics. Table I provides a list of the main variables used and associated descriptive statistics.

\subsection{Method of estimation}

Many kinds of data used in the social sciences have a hierarchical formation. Most of the research in housing studies overlooks the hierarchical or clustered structure of the data, and this may cause failure or flaws in the results of these models. However, these kinds of drawbacks can be overcome with the help of multi-level modelling, which allows us to analyze hierarchical data structures or variables at different levels. This method provides an analysis of the individual-level dependent variables by using combinations of individual and group-level independent variables and also analyzes the complex data that have a hierarchical structure. Multi-level models are also known in the literature as contextual models, hierarchical linear models, hierarchical linear regression, random coefficients models, hierarchical mixed linear models or Bayesian linear models.

Usually in social science studies, the hierarchical structure of data consists of lower and upper levels. The lower level consists of individuals or properties which are grouped in higher levels with respect to the context. Because multi-level analysis involves individuals that are nested in a contextual level, this method often attempts to examine how the individual-level (micro-level) outcomes are affected by both the individual- and group-level (macro-level or contextual-level) variables.

With respect to the fact that individual observations nest in contextual perspectives, this statistical method helps to specify effects of wider contextual factors on individual-level outcomes. Thus, it becomes possible to display the different relationships between the dependent and independent variables within different contextual groups. These kinds of relationships are referred to as contextual effects, and these are the effects that a space has on individuals. On the other hand, compositional effects are the effects that the characteristics of individuals in different geographical levels have. According to Blalock (1984, p. 354):

$[\ldots .$. the essential feature of all contextual-effects models is an allowance for macro processes that are presumed to have an impact on the individual actor over and above the effects of any individual-level variables that may be operating.

Multi-level modelling is developed from hierarchical approaches that can include both fixed and random effects, which can be modelled at each level of the hierarchy. Fixed effects refer to the "permanent" or "unchanging/constant/fixed" part of the equations so that one estimate is derived for the whole sample, whereas random $(\mathrm{R})$ effects refer to the "allowed to vary" part 


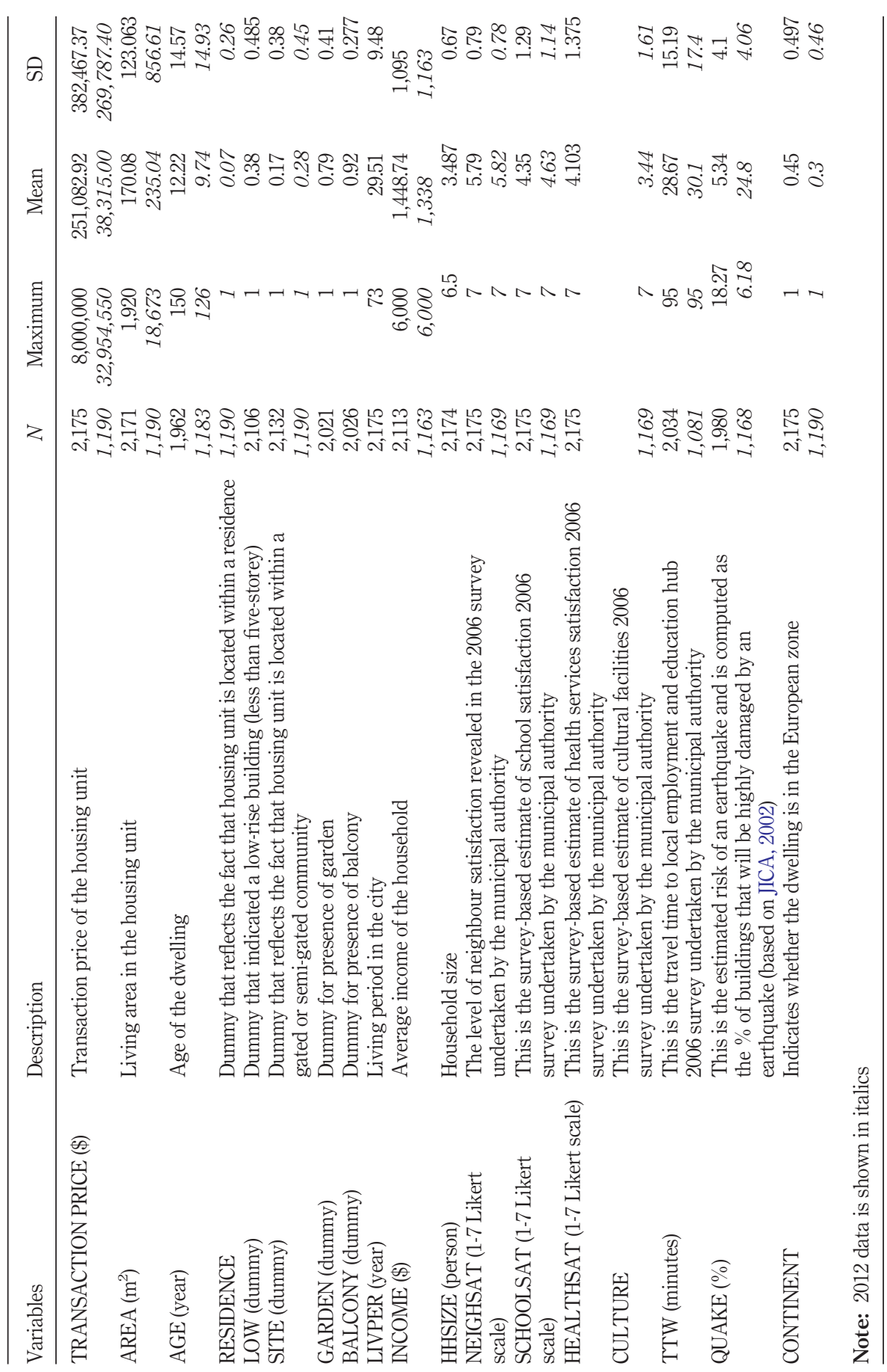

Earthquake activity

81
Table I.

Descriptive statistics for 2007 and 2012 samples 
JERER 10,1

82

so that there is potential for different results to occur within the sample (Jones and Bullen, 1993).

Multi-level modelling can be considered a modified version of hedonic price modelling as it has the same general structure, consisting of fixed and random effects. In a hedonic equation, a model is estimated that contains only fixed effects - the intercept and coefficients describe the sample as a whole. However, the spatial pattern of house price is not adequately captured by fixed effects in regression models, which assumes that the same intercept and slopes characterize all neighbourhoods in this analysis. An alternative way to model the tendency towards spatial distribution of housing prices in different parts of the city and to reduce the spatial autocorrelation problem is to allow each of the neighbourhoods to have its own random intercept instead of the fixed effects regression model. Multi-level modelling takes different nested levels into account by disaggregating the variance to these levels. It allows the use of both individuals (housing units) and groups of individuals (neighbourhoods) in the same model, which avoids flouting the assumption of independent cases, as standard error of any results can be affected by the clustered nature of the data (Gorard, 2003). Furthermore, multi-level modelling allows analyzing the within-group and between-group variation and to what extend these variables belong to individual (housing unit) or group (neighbourhood) variables.

The disaggregation of variance in the levels is one of the remarkable differences between a multi-level and hedonic model. The multi-level modelling approach allows the decomposition of residuals to expose random intercepts and hedonic slope parameters that are unique to each defined spatial area (Leishman et al., 2013). By including a set of coefficients that represents the whole city and also a random intercept which varies from one neighbourhood to another, a multi-level equation can be obtained, which is formulated as:

$$
\mathrm{Yij}=\alpha \mathrm{j}+\sum \beta \mathrm{j} \mathrm{Xij}+\mathrm{eij}
$$

where Yij represents the price of house $\mathrm{i}$ in place $\mathrm{j}$, eij represents the error term (the difference between the predicted and the actual price of house $i$ in place $j$ ), $\alpha \mathrm{j}$ is the intercept (the value of $\mathrm{Y}$ when all housing attributes are 0 ) and $\beta \mathrm{j}$ is the slope, place-specific parameter.

$$
\alpha \mathrm{j}=\alpha+\mu \mathrm{j}
$$

and

$$
\beta \mathrm{j}=\beta \mathrm{i}+\mu \mathrm{j} \beta
$$

To make it clear, it can be assumed that $\beta j$, the average price of a detached house in place $j$, is a function of the market-wide average price of houses $\beta i$ plus $\mu j \beta$, which is a varying difference for each of the places.

Therefore, the final version of a multi-level is:

$$
\mathrm{Y}_{\mathrm{ij}}=\alpha_{\mathrm{j}}+\sum \beta_{\mathrm{i}} \mathrm{X}_{\mathrm{ij}}+\left(\varepsilon_{\mathrm{ij}}+\mu_{\mathrm{j}} \alpha+\mu_{\mathrm{j}} \beta \mathrm{X}_{\mathrm{ij}}\right)
$$

In this formulation, it can be assumed that $\mathrm{Y}_{\mathrm{ij}}$ represents the price of the house $i$ in area $j ; \alpha$, $\beta$ and $\mu$ are the parameters to be estimated, $\varepsilon$ is the error term and $\mathrm{X}_{\mathrm{ij}}$ is a set of explanatory variables which include housing attributes, socio-economic characteristics and earthquake risk of the house $i$ in area $j$. 


\section{Model results and research findings}

The data set was analyzed using the software package STATA. The data set used in this study comprises two levels (housing unit and neighbourhood) of observation. The multi-level model results, shown in Table II, provide fixed effects and model fit statistics for a period (2007) prior to a shock to perceptions of the risk of earthquake damage and also for a period (2012) after recent earthquake activity in the wider geography region. The coefficients shown in Table II are analogous to hedonic coefficients from a regression model. The model operates like a hedonic in that it isolates the earthquake risk from other price activity determinants. It also allows the differentiation between market-wide effects $(-0.19$ per cent discounts) and random $(\mathrm{R})$ neighbourhoods effects (which can be + where risk is below the market average or - where risk is above the average).

Table II shows that the results are generally stable between these two periods. Many variables, including living area of the housing unit, being located at a semi-gated or gated community, income of the household and earthquake risk, have a significant impact on prices in both the 2007 and 2012 periods. The variable, Quake, is clearly important to the model given the task at hand. This variable is based on an assessment of how likely earthquake activity might be and what proportion of buildings might be damaged. The models capture the different ways that variable impacts on house prices, even after we control for changes in other relevant price determinants. The usefulness model is, of course, dependent on the reliability of this measure. The estimates are produced by JICA, which is an institution that provides official Japanese development assistance, including technical support in disaster relief contexts. We contend that it represents a very robust proxy measure of the probability and scale of possible earthquake damage.

The main difference between 2007 and 2012 is the influence of the age of the housing unit. This implies that there is an increasing tendency of preferring new buildings. The structural

\begin{tabular}{lcc}
\hline Variable & Coefficient (2007) & Coefficient (2012) \\
\hline Constant & 2.196529 & 2.159938 \\
Area & $1.045023^{*}$ & $0.93688^{*}$ \\
Age & -0.0024381 & $-0.06287^{*}$ \\
Residence & - & $0.214118^{*}$ \\
Garden & $0.0347619^{*}$ & - \\
Low & 0.0096652 & - \\
Site & $0.113051^{*}$ & $0.0813993^{*}$ \\
Income & $0.195355^{*}$ & $0.48089^{*}$ \\
Hhsize & $-0.486838^{*}$ & - \\
Schoolsat & 0.0931491 & 0.09797 \\
Neigsat & 0.081995 & -0.03098 \\
Culturesat & - & 0.571796 \\
Livper & 0.1556817 & - \\
Ttwork & - & 0.049677 \\
Quake & $-0.1642557^{*}$ & $-0.196622^{*}$ \\
Continent & $0.1085348^{*}$ & -0.0417574 \\
Wald $\chi^{2}$ & $2,690.26^{*}$ & $1,310.21^{*}$ \\
Log restricted likelihood & $632.96615^{*}$ & $147.98648^{*}$ \\
Groups & 270 & 278 \\
N & 1,825 & 1,070
\end{tabular}

Notes: *Indicates significance at the $5 \%$ level; - indicates that the variable is excluded because of multicollinearity

Table II.

Multi level model: fixed effects and model fit statistics 
JERER

10,1

84

quality of buildings, which is likely to be an important factor, is not measured directly in the equation. The influence of structure quality, however, may be captured in part by the premium for new homes and also for the negative effects of some neighbourhoods where there are significant levels of informal housing. In both periods, the Wald $\chi^{2}$ tests suggest strong explanatory power.

The models show that the impact of earthquake risk changes between periods. The results show that in 2007, a 0.164 per cent discount in house price would be expected for a 1 per cent increase in the likelihood that a dwelling might be damaged. In 2012, the deflationary price effect becomes larger and rises to a 0.196 per cent discount for every 1 per cent increase in the earthquake risk. This impact is statistically significant in both time periods. The likelihood ratio test confirms that this random intercepts model offers significant improvement over a linear regression model with fixed effects only (Table III).

Table IV summarizes the impact of earthquake risk on the five neighbourhoods that had the highest house price levels in 2007. It shows that these neighbourhoods with have positive random effect ( $R$ effect in the table below) values and that the risk of earthquake is low both for 2007 and 2012 periods.

Table V shows the impact of earthquake risk on the five lowest-priced neighbourhoods. This shows that the cheapest neighbourhoods have mainly negative random $(R)$ effect values, implying significant price discounts. The changes in these values reflect the high assessed risk of earthquake damage for both periods. The impact is heightened after the most recent earthquake activity in the region.

Thus, it is clear that the impact of earthquake risk is most pronounced in lower-priced neighbourhoods. This was true both before and after the most recent activity. It is also clear that since the recent activity, even though this has had a moderate general dampening impact on the market, there has been a markedly more pronounced effect in neighbourhoods at the bottom end of the market price spectrum. Again, the influence of structure quality and the presence of informal housing and lower specification structures is likely to provide part of the explanation, even though these factors are not directly captured within the model. It may also be argued that the differential way in which perceived risk is capitalized is evidence of non-rational behaviour on the part of buyers and investors.

\section{Conclusion}

Modelling house prices across spatially segmented housing markets is a complex task. But,

it is a task that is important in contexts where there are spatially differentiated risks of

\begin{tabular}{|c|c|c|c|c|}
\hline & \multicolumn{2}{|c|}{2007} & \multicolumn{2}{|c|}{2012} \\
\hline & Estimate & Standard error & Estimate & Standard error \\
\hline Constant & 0.1254122 & 0.0260374 & 0.0008076 & 0.3247712 \\
\hline Residence & & & 0.22841 & 0.0506395 \\
\hline Area & & & $1.00 \mathrm{E}-01$ & $8.72 \mathrm{E}-03$ \\
\hline Income & & & 0.0243879 & 0.0203682 \\
\hline Site & & & $1.52 \mathrm{E}-01$ & 0.0291819 \\
\hline Continent & & & 1.54E-01 & 0.0482713 \\
\hline Neighsat & 0.1405585 & 0.0508316 & & \\
\hline Schoolsat & 7.11E-08 & 0.0001425 & & \\
\hline Quake & $6.62 \mathrm{E}-11$ & $7.82 \mathrm{E}-11$ & $5.74 \mathrm{E}-02$ & 0.1063757 \\
\hline Lr Test & \multicolumn{2}{|c|}{$\begin{array}{c}\chi^{2}(4)=680.93 \\
\operatorname{Prob}>\chi^{2}=0000\end{array}$} & \multicolumn{2}{|c|}{$\begin{array}{c}\chi^{2}(7)=531.02 \\
\text { Prob }>\chi^{2}=000\end{array}$} \\
\hline
\end{tabular}

Table III.

Multi-level model random effects 


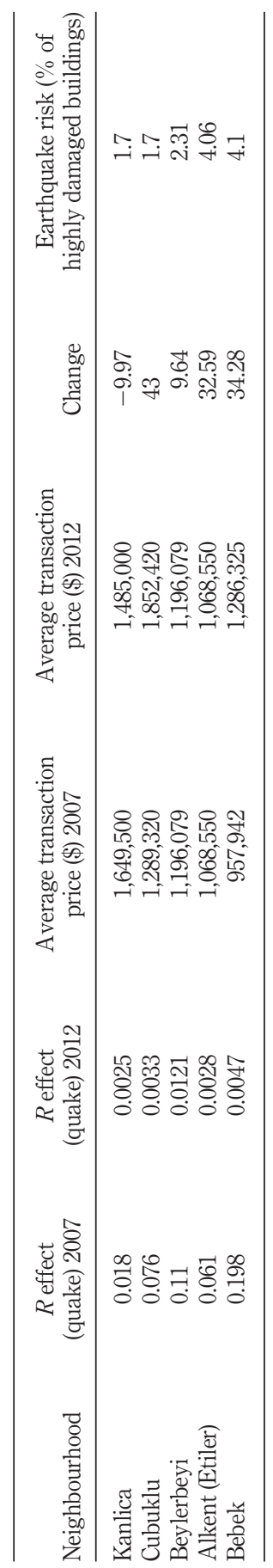

Earthquake activity

85

Table IV. Impact of earthquake risk on high-priced five neighbourhoods 
JERER

10,1

86

Table V.

Impact of earthquake risk (the top five

neighbourhoods with

lowest transaction

price - 2007 period)

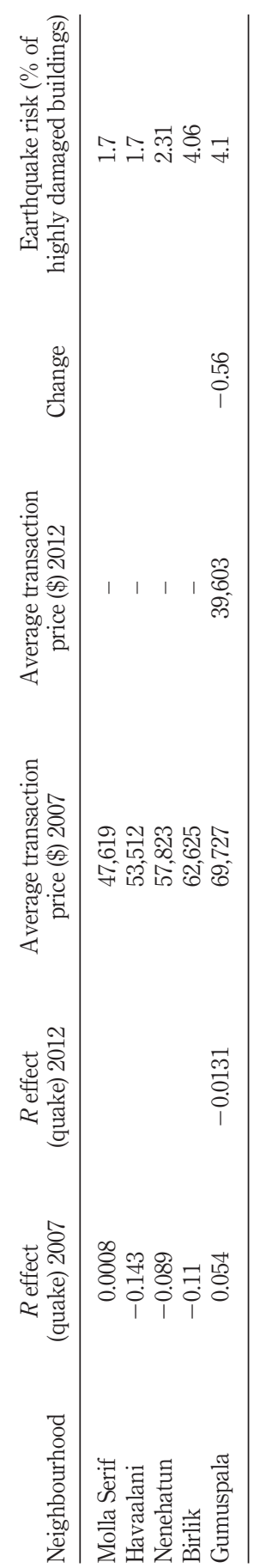


damage or differential exposure to negative environmental externalities such as flood risk, hazardous waste sites or air pollution. The ability to differentiate impacts of these sorts in a granular way is limited when applying standard hedonic regression methods. Using Istanbul as a case study, we seek to address this challenge by using a multi-level model within an event study framework. This approach has been shown in these circumstances to be able to distinguish between the different level impacts and to have high predictive power.

Specifically, this paper shows that within the Istanbul housing market, multi-level modelling could be a useful extension to standard hedonic modelling in understanding the differential spatial impact of earthquakes on neighbourhood pricing. In broad terms, and in line with other forms of house price model, the perception of changes in house price (risk) from the impact of earthquakes is assumed to be internalized into the home buying process. This standard hedonic assumption reveals that earthquake effects could be observed at both the citywide level and the neighbourhood level. The effect at the neighbourhood level varied widely, suggesting that while the impact of an earthquake could be felt across the city, there were discrete spatial impacts on house prices. This finding is significant for models utilized in earthquake zones, as it suggests that using a single model-wide variable for earthquake risk is likely to adversely affect the predictive power of the method across neighbourhoods. Furthermore, attempts to accommodate submarkets within hedonic methods have only limited predictive power (Leishman et al., 2013). This research supports the extension of hedonic models to isolate neighbourhood effects from higher-level (urban or regional) effects.

We test our approach empirically using data from Istanbul. Istanbul, of course, has not been directly impacted by earthquake activity since the 1999 Marmara earthquake. It does, however, provide a useful case study in that the Van earthquake in Eastern Turkey in 2011 has served to raise awareness of earthquake risk among house purchasers and valuers operating within the market. This allows us to empirically test the hypotheses that, first, perceptions of earthquake risk might have changed when compared to the period prior to the Van event and, second, that the impacts of any change in perceived risk will be spatially variable.

We argue that the approach used, combining multi-level models in an event study framework, is particularly suitable for benchmarking and exploring any changes in what might be expected to be highly spatially granular impacts on different parts of the housing market. One advantage of multi-level modelling is its ability to cope with fewer numbers of individual observations as long as the number of groups is high enough to analyze the variation between groups at a particular level. Specifically, where it is probable that the impact will vary across a significant number of geographic sub-areas (because of existing submarkets or because the impact would be distributed unevenly), then extending the standard regression model to include multiple levels appears to enhance explanatory power.

\section{References}

Adair, A., Berry, J. and McGreal, W.S. (1996), "Hedonic modelling, housing submarkets and residential valuation", Journal of Property Research, Vol. 16 No. 1, pp. 67-83.

Alkay, E. (2008), "Housing submarkets in Istanbul", International Real Estate Review, Vol. 11 No. 1, pp. 113-127.

Alkay, E. (2011), "The residential mobility pattern in the Istanbul Metropolitan Area”, Housing Studies, Vol. 26 No. 4, pp. 521-539.

Alkay, E., Keskin, B. and Watkins, C. (2015), "Explaining spatial variation in housing construction activity in Turkey", paper presented at the European Real Estate Society Conference, Istanbul, July. 
JERER

10,1

88

Ballas, D. and Tranmer, M. (2008), Happy Places or Happy People? A Multi-Level Modelling Approach to The Analysis of Happiness and Well-Being, University of Sheffield, Mimeo.

Beron, K.J., Murdoch, J.C., Thayer, M.A. and Vijverberg, W.P.M. (1997), "An analysis of the housing market before and after the 1989 Loma Prieta earthquake", Land Economics, Vol. 73 No. 1, pp. 101-113.

Bibbee, A., Gonenc, R., Jacobs, S., Konvitz, J. and Price, R.W.R. (2000), "The economic effects of the 1999 Turkish earthquakes: an interim report", OECD Economics Working Papers.

Bin, O., Brown Kruse, J. and Landry, C.E. (2008), "Flood hazards, insurance rates, and amenities: evidence from the coastal housing market", The Journal of Risk and Insurance, Vol. 75 No. 1, pp. 63-82.

Blalock, H.M. (1984), “Contextual-effects models: theoretical and methodological issues”, Annual Review of Sociology, Vol. 10, pp. 353-372.

Boyle, M. and Kiel, K. (2001), "A survey of hedonic studies of the impact of environmental externalities”, Journal of Real Estate Literature, Vol. 9, pp. 117-144.

Building Census (2000), Building Census, State Institute of Statistics, Prime Ministry Republic of Turkey, Ankara, available at: www.tuik.gov.tr/IcerikGetir.do?istab_id=64 (accessed 17th December 2014).

Case, B., Colwell, P., Leishman, C. and Watkins, C. (2006), "The impact of environmental contamination on condo prices: a hybrid repeat-sale/hedonic approach”, Real Estate Economics, Vol. 34 No. 1, pp. 77-107.

Clapp, J.M. (2003), "A semiparametric method for valuing residential locations: application to automated valuation", Journal of Real Estate Finance and Economics, Vol. 27 No. 3, pp. 303-320.

Coskun, Y. (2011), "The global financial crisis and the Turkish housing market", Housing Finance International, Vol. 25 No. 3, pp. 6-14.

Des Rosiers, F. and Theriault, M. (2008), "Mass appraisal, hedonic price modelling and Urban externalities: understanding property value shaping processes", in Kauko, T. and d'Amato, M. (Eds), Mass Appraisal Methods, An International Perspective for Property Valuers, RICS Research, Wiley-Blackwell, Hoboken.

Feng, Y. and Jones, K. (2016), "Comparing two neighbourhood classifications: a multilevel analysis of London property price 2011-2014", paper presented at the Pacific Rim Real Estate Conference, Queensland, January.

Fik, T., Ling, D. and Mulligan, G. (2003), "Modeling spatial variation in housing prices: a variable interactions approach", Real Estate Economics, Vol. 31 No. 4, pp. 623-646.

Fletcher, M., Gallimore, P. and Mangan, J. (2000), “The modelling of housing submarkets”, Journal of Property Investment and Finance, Vol. 18 No. 4, pp. 473-487.

Gokmen, G.P., Yuksel, D.Y., Erkok, F., Alkiser, Y. and Keskin, B. (2006), "Evaluating and reducing earthquake risks of squatter settlements in Istanbul”, Open House International, Vol. 31 No. 1, pp. 116-124.

Goodman, A. and Thibodeau, T. (2003), "Housing market segmentation and hedonic prediction accuracy", Journal of Housing Economics, Vol. 12 No. 3, pp. 181-201.

Gorard, S. (2003), "What is multi- level modelling for?", British Journal of Educational Studies, Vol. 51 No. 1, pp. 46-63.

Grigsby, W. (1963), Housing Markets and Public Policy, University of Pennsylvania Press, Pennsylvania.

Hallstrom, D.G. and Smith, K. (2005), "Market response to hurricanes", Journal of Environmental Economics and Management, Vol. 50 No. 3, pp. 541-561.

JICA (2002), A Disaster Prevention/Mitigation Plan for Istanbul, Report to Istanbul Municipal Authority, Istanbul, available at: www.ibb.gov.tr/tr-TR/SubSites/DepremSite/Publishing Images/JICA_ENG.pdf (accessed 20th July 2014). 
Jones, K. and Bullen, N. (1993), "A multilevel analysis of the variations in domestic property prices Southern England, 1980-1987”, Urban Studies, Vol. 30 No. 8, pp. 1409-1426.

Keskin, B. (2010), “Alternative approaches to modelling housing market segmentation: evidence from Istanbul", Unpublished $\mathrm{PhD}$ Thesis, University of Sheffield, Sheffield.

Keskin, B. and Watkins, C. (2014), The Impact of Earthquake Risk on Property Values, Royal Institution of Chartered Surveyors, London.

Keskin, B. and Watkins, C. (2016), "Defining spatial housing markets: exploring the case for expert delineated boundaries", Urban Studies, online first, January, pp. 1-17.

Lamond, J., Proverbs, D. and Hammond, F. (2010), "The impact of flooding on the price of residential property: a transactional analysis of the UK market", Housing Studies, Vol. 25 No. 3, pp. 335-356.

Leishman, C. (2009), "Spatial change and the structure of urban housing sub-markets", Housing Studies, Vol. 24 No. 5, pp. 563-585.

Leishman, C., Costello, G., Rowley, S. and Watkins, C. (2013), "The predictive performance of multi-level models of housing submarkets: a comparative analysis", Urban Studies, Vol. 50 No. 6, pp. 1201-1230.

Loomis, J. (2004), “Do nearby forest fires cause a reduction in residential property values?”, Journal of Forest Economics, Vol. 10 No. 3, pp. 149-197.

MacDonald, D.N., Murdoch, J.C. and White, H.L. (1987), “Uncertain hazards, insurance, and consumer choice: evidence from housing markets”, Land Economics, Vol. 63 No. 4, pp. 361-371.

Maclennan, D. and Tu, Y. (1996), "Economic perspectives on the structure of local housing markets", Housing Studies, Vol. 11 No. 3, pp. 387-406.

Malpezzi, S. (2003), "Hedonic pricing models: a selective and applied review", in O'Sullivan, T. and Gibb, K. (Eds), Housing Economics and Public Policy, Blackwells, Oxford.

Mueller, J., Loomis, J. and Gonzalez-Caban, A. (2009), "Do repeated wildfires change homebuyers' demand for homes in high-risk areas? A hedonic analysis of the short and long-term effects of repeated wildfires on house prices in Southern California", Journal of Real Estate Finance and Economics, Vol. 38 No. 2, pp. 155-172.

Nakagawa, M., Saito, M. and Yamaga, H. (2007), "Earthquake risks and housing rents: evidence from the Tokyo Metropolitan Area", Regional Science and Urban Economics, Vol. 37 No. 1, pp. 87-99.

Naoi, M., Seko, M. and Sumita, K. (2009), "Earthquake risk and housing prices in Japan: evidence before and after massive earthquakes", Regional Science and Urban Economics, Vol. 39 No. 6, pp. 658-669.

Onder, Z., Dokmeci, V. and B. Keskin (2004), "The impact of public perception of earthquake risk on Istanbul's housing market”, Journal of Real Estate Literature, Vol. 12 No. 2, pp. 181-194.

Orford, S. (1999), Valuing the Built Environment: GIS and House Price Analysis, Ashgate, Aldershot.

Palm, R. (1981), "Public response to earthquake hazard information", Annals of the Association of American Geographers, Vol. 71 No. 3, pp. 389-399.

Pavlov, A.D. (2000), "Space-varying regression coefficients: a semi-parametric approach applied to real estate markets", Real Estate Economics, Vol. 28 No. 2, pp. 249-283.

Pryce, G. (2013), "Housing submarkets and the lattice of substitution", Urban Studies, Vol. 50 No. 13, pp. 2682-2699.

Ridker, R.G. and Henning, J.A. (1968), "The determination of residential property value with special reference to air pollution", Review of Economics and Statistics, Vol. 49, pp. 246-257.

Simmons, K.M., Kruse, J.B. and Smith, D.A. (2002), "Valuing mitigation: real estate response to hurricane loss reduction measures", Southern Economic Journal, Vol. 68 No. 3, pp. 660-671.

Stetler, K.M., Venn, T.J. and Calkin, D.E. (2010), "The effects of wildfire and environmental amenities on property values in northwest Montana, USA", Ecological Economics, Vol. 69 No. 11, pp. 2233-2243. 
JERER

10,1

90

Subramanian, S.V. (2010), "Multilevel modelling”, in Fischer, M.M. and Getis, A. (Eds), Handbook of Spatial Analysis: Software, Tools, Methods and Applications, Springer-Verlag, Berlin.

Tu, Y. (2003), "Segmentation, adjustment and disequilibrium”, in O'Sullivan, T. and Gibb, K. (Eds), Housing Economics and Public Policy, Blackwells, Oxford.

Watkins, C. (1999), "Property valuation and the structure of urban housing markets", Journal of Property Investment and Finance, Vol. 17 No. 2, pp. 157-175.

Watkins, C.A. (2001), "The definition and identification of housing submarkets", Environment and Planning A, Vol. 33 No. 12, pp. 2235-2253.

Watkins, C. (2012), "Housing submarkets”, in Smith, S. (Eds), International Encyclopeadia of Housing and Home, Elsevier, North-Holland.

Wenzel, F., Daniell, B., Khaza, T., Kunz-Plapp, T. and Daniell, J.E. (2012), "The CEDIM forensic earthquake analysis group and the test case of the 2011 van earthquakes", 15th WCEE Meeting, Lisbon.

Willis, K.G. and Asgary, A. (1997), "The impact of earthquake risk on housing markets: evidence from Tehran real estate agents", Journal of Housing Research, Vol. 8 No. 1, pp. 125-136.

\section{Further reading}

Kauko, T. and d'Amato, M. (2011), "Neighbourhood effects in international encyclopedia of housing and home”, in Smith, S.J., Elsinga, M., Eng, O.S., Watcher, S. and O’Mahoney, L.F. (Eds), Elsevier Publisher, Cambridge.

Schnare, A. and Struyk, R. (1976), "Segmentation in urban housing markets", Journal of Urban Economics, Vol. 3, pp. 146-166.

Straszheim, M. (1975), An Econometric Analysis of the Urban Housing Market, National Bureau of Economic Research, New York, NY.

Venn, T.J. and Calkin, D.E. (2011), "Accommodating non-market values in evaluation of wildfire management in the United States: challenges and opportunities", International Journal of Wildland Fire, Vol. 20, pp. 327-339.

\section{Corresponding author}

Berna Keskin can be contacted at: b.keskin@sheffield.ac.uk

For instructions on how to order reprints of this article, please visit our website:

www.emeraldgrouppublishing.com/licensing/reprints.htm

Or contact us for further details: permissions@emeraldinsight.com 